\title{
Aportacions a l'estudi de la literatura medieval
}

\section{Contributions to the study of medieval literature}

\author{
Alaitz Zalbidea Berenguer \\ alaitz.zalbideaberenguer@uchceu.es \\ Universitat Cardenal Herrera \\ CEU - València
}

La nostra literatura medieval és, sense cap dubte, el fragment de la nostra història literària que més estudis i més curiositat ha despertat entre els investigadors, des de sempre. Per damunt de qualsevol altre període, el món medieval ha exercit i exerceix una fascinació notable sobre les societats contemporànies $i$, en el cas de la nostra, més encara. I això perquè a més que el món dels cavallers i les dames, dels trobadors i la concepció de l'amor quasi com ens ha arribat a nosaltres, ara, va ser mitificat pels homes del romanticisme, va ser consagrat per la renaixença i, encara, durant el segle XX va estar el referent de moltes particularitats que els qui parlem la nostra llengua reconeixem com a pròpies i privatives de la nostra cultura.

Tirant lo Blanch, Ausiàs March, Jaume Roig o Isabel de Villena són noms que sonen encara avui i, al seu costat, Francesc Eiximenis, sant Vicent Ferrer, Ramon Muntaner, Jordi de Sant Jordi, Bernat Metge, el Curial... Són autors i obres que formen part de l'univers literari dels catalans, dels valencians i dels balears; però, encara més, formen part del seu univers quotidià, pràcticament. $\mathrm{Al}$ costat de Jaume I, que per als mallorquins i els valencians és sinònim de l'origen dels seus territoris i, per als catalans, representa un moment important en la història de la Corona d'Aragó. I, per això, aquests noms -i encara d'altres- han passat a significar, també, carrers i places, avingudes, escoles, instituts, societats culturals, biblioteques, sales distingides en institucions públiques o institucions senceres i, fins i tot, universitats. El món medieval, representat en aquells que ens varen deixar un llegat escrit, és -per dir-ho d'alguna manera- ben viu.

Tot aquest interés a què ens referíem ve originat, també, perquè des de les instàncies on ssinvestiga, on es forma els futurs docents i on, en definitiva, es dissenya bona part de la cultura, la voluntat de 
conéixer i difondre aquell passat literari no ha deixat de produir textos: no ha deixat de produir tesis doctorals, llibres i articles que, amb la seua difusió més o menys efectiva, a la llarga va fonamentant tota aquesta cultura de masses que es veu identificada amb els noms suara dits i que, en certa manera, reconeix en ells uns trets identificadors de la seua pròpia identitat. I més que ho farà, conforme passen els anys.

Per això, des de les pàgines virtuals de la revista Scripta, oferir un dossier monogràfic sobre la literatura medieval, sense més adjectius, ens semblava ben interessant, atés que el treball, al remat, vindria a unir-se a tota una línia de recerques que es capbussa en els manuscrits i en les edicions incunables, s'impregna de la documentació d'aquells segles fins fa no res qualificats d'obscurs i intenta aportar llum als més diversos interrogants. A uns interrogants com aquells als quals s'han enfrontat els autors del present aplec, que passem a comentar.

Així, en primer lloc ens trobem amb l'aportació d'Ángel Narro, de la Universitat de València, que analitza i compara els principals tòpics retòrics presents als pròlegs dels textos hagiogràfics bizantins i catalans. El punt des d'on es parteix és la consolidació del gènere hagiogràfic en la literatura grega tardo-antiga i d'època bizantina i la seua influència sobre el desenvolupament de l'hagiografia occidental, primer en llatí i després en les llengües romàniques, ja en època medieval. Totes dues hagiografies mostren un repertori de tòpics ben semblants. Per una altra part, l'investigador Albert Toldrà, analitza una llegenda medieval que fusiona dos personatges literaris: el Judes dels evangelis i l'Èdip clàssic de la tragèdia de Sòfocles, de manera que ens trobem un Judes que, als pecats que ja li coneixíem (traïció, avarícia, mentida, satanisme, suïcidi, etc.), li hem d'afegir dues trangressions més i, ara, "edípiques": el parricidi -perquè mata el seu pare- $i$ l'incest -atés que es casa amb sa mare-. Entre el segle XII i el XVI, ho trobarem, especialment en els textos de les "passions" teatrals occitanes i catalanes, la Legenda aurea de Varazze i, encara, en referències detectades en els sermons de sant Vicent Ferrer i en els escrits de Francesc Eiximenis. en tercer lloc, Abel Soler, de la Universitat de València, fa una nova incursió en l'obra que fns ara s'havia considerat anònima: Curiale Gü̈lfa, novel la cavalleresca qeu ara es considera escrita en català i atribuïble al gran camarlenc del Nàpols d'Alfons el Magnànim, Enyego d'Àvalos, on es poden trobar mites ovidians tergiversats satíricament; teofanies i decorats neoplatònics; remissions explícites i/o implícites de Cèsar, Macrobi, Plató, Apuleu, etc., que no resulten en absolut prescindibles, i que ara són vistos com una altra manera d'evocar-hi els clàssics que no s'explicaria sense considerar els contactes de l'hipotètic escriptor amb l'humanisme llombard i napolità i, encara, pel repertori de clàssics grecollatins documentats a la biblioteca personal del mateix D’Àvalos, que evidencia la coincidència de gustos i lectures d'aquest amb l'anònim del Curiali fa que Soler es ratifique en l'atribució de l'autoria. D'altra banda, l'investigador de l'Institut Universitari Menéndez Pidal (Universitat Complutense de Madrid), Jeroni Miguel, s'acosta també al Curial e Güelfa on, més enlla de la modernitat del text, adverteix que conserva reminiscències ben medievals, pròpies del gènere cavalleresc que la caracteritza, $\mathrm{i}$ que la situa en l'ambient humanista de la Itàlia del segle XV. I això, tant per les fonts utilitzades, com per molts dels temes que hi apareixen. La mateixa trajectòria del personatge central ens el mostra 
realitzant gestes cavalleresques, però també estudiant i adonant-se'n que només mitjançant l'esforç que porta a la virtus podrà obtenir la necessària nobilitas, cosa que el farà una persona íntegra i apta per meréixer l'amor de la Güelfa. Encara, Anna Maria Compagna, de la Univesità di Napoli Federico II, també fa un acostament al Curial, tot posant-lo en contacte amb dos altres personatges de la literatura medieval en català: Jacob Xalabín i Tirnat lo Blanch. I així, identifica la identitat múltiple i l'apertura cultural del procés de formació del protagonista, en el seu ascens econòmic i social. L'evolució del protagonista, gràcies a un mecanisme psicològic, que ara podem reconéixer, permet assolir els objectius esperats, a la fi de la novel la, ben al contrari dels altres dos personatges amb què se'l compara: Jacob i Tirant, que es mantenen sempre iguals. Un altre treball, d'Antoni Mas i Miralles, de la Universitat d'Alacant, fa una aproximació al lèxic botànic en el Libre de Caça i als termes corresponents en altres tractats romànics, cosa que ens permet veure com aquell tractat de falconeria, que es dedica a descriure els símptomes i malalties que patien les aus i a oferir com a cures pal liatives diferents remeis terapèutics a partir de les plantes medicinals, pot ser contemplat, ara, com una font interessant de termes botànics que podem comparar amb els corresponents d'altres obres de falconeria medieval en quatre llengües romàniques: portuguès, castellà, francès i italià. De cada terme s'exposa quines propietats curatives tenia, el nom científic de la planta de què procedeix, l'etimologia del mot i l'ètim estàndard actual. Per últim, Rubén Galera Hernàndez, de la Universitat Catòlica de València Sant Vicent Màrtir, s'acosta a la política expansionista de la Corona d'Aragó a Itàlia, encapçalada per Alfons el Magnànim durant la primera meitat del segle XV, i observa com la seua cort fou un focus de coneixement dels grans autors clàssics llatins i grecs. Això, gràceis a una nòmina abundosa de lletraferits com Lorenzo Valla, Guiniforte Barzizza, Bartolomeo Facio i Antonio Beccadelli (el Panormita), qeu varen estar en contacte permanent amb membres de la cancelleria reial i de la noblesa. Un d'aquells nobles va ser el cavaller valencià Francesc-Gilabert de Centelles i Queralt, altrament dit Ramon de Riu-sec, senyor de Nules i comte d'Oliva (1449), el qual va mantenir correspondència epistolar amb Barzizza i Beccadelli, per demanar-los consell sobre la naturalesa de l'amor. En aquest article, doncs, s'estudien les fonts de consulta a què va recórrer el Panormita, quan va redactar l'epístola per al Centelles i això es contextualitza amb la realitat amorosa del cavaller valencià.

Al remat, un total de set articles que abasten diversos temes d'interés en l'estudi de la nostra literatura medieval i que ens ofereixen un panorama enriquidor, en el senti que ens mostren com les aproximacions al món dels segles medievals sempre pot oferir-nos noves dades. nous temes de reflexió i, en definitiva, un millor coneixement de la nostra literatura del passat. 